\title{
INTERFERENCE WITH REPRODUCTION IN WATER BUFFALO BY INTRA-UTERINE DEVICES
}

\author{
K. JANAKIRAMAN, G. O. WOODY,* S. P. AGARWAL, R. G. BHALLA,* \\ K. P. SHUKLA, B. A. GADGIL, N. G. BUCH $\dagger$ AND L. E. GASIDA $\ddagger$ \\ Reproductive Biology Unit, Institute of Agriculture, Anand, India
}

(Received 16th Fuly 1969, revised 29th September 1969)

\begin{abstract}
Summary. The effects of IUDs on the occurrence of ovulation and the pituitary gonadotrophin content was studied in water buffalo heifers of the Surti breed. Thirty-six of these heifers were divided into four equal groups. Group 1 received sham operations, while Groups 2, 3 and 4 were fitted with plastic IUDs in the cranial region of the uterus either ipsilaterally or contralaterally (in relation to the side on which ovulation occurred) or bilaterally, $72 \mathrm{hr}$ after the exhibition of heat. Treated heifers showed significantly shorter cycles than the controls $(P<0 \cdot 01)$. There was no difference between Groups 2, 3 and 4 . Heifers were slaughtered after the onset of heat in post-IUD-insertion cycles. Eight of the nine heifers ovulated in the control group, but only three in the group fitted with bilateral IUDs and one each in the groups fitted with ipsilateral and contralateral IUDs. The other ovarian characters studied did not show any significant differences among the four groups.

The anterior pituitaries from these heifers in different groups were freeze-dried and assayed for LH and FSH. Neither LH nor FSH activity was statistically different among treatment groups.

The results of this experiment suggested that an IUD, when present in one horn, also affects the adjacent ovary of the opposite horn to induce shorter cycles. This contralateral effect may be mediated systemically either at the level of the pituitary, the hypothalamus, or both. It is not possible to rule out transmission of a uterine factor from the IUDhorn to the non-IUD horn.
\end{abstract}

\section{INTRODUCTION}

Intra-uterine devices (IUDs) exert a contraceptive action in all species so far studied but do not affect the sexual cycle length in woman, monkey, pig or rat. They do cause shorter cycles in the ewe, cow, guinea-pig, water buffalo (reviewed by Marston \& Kelly, 1966; Kar, 1968) and goat (Gadgil, Collins \& Buch, 1968). An IUD in the uterine horn on the same side as that on which ovulation occurs exerts a greater effect than when it is present in the opposite horn in the

* Present address: Reproductive Physiology Programme, University of Wisconsin, Madison, U.S.A.

+ Present address: Gujarat College of Veterinary Science and Animal Husbandry, Anand, India.

†resent address: Laboratory of Genetics, University of Wisconsin, Madison, U.S.A. 
guinea-pig (Ginther, Mahajan \& Gasida, 1966b), ewe (Ginther, Pope \& Casida, 1966c) and cow (Ginther, Woody, Janakiraman \& Casida, 1966d), but Gadgil et al. (1968) were unable to show a similar effect in the goat. IUDs have also been shown to influence pituitary gonadotrophic activity in the cow (Horie, Ishikura \& Metsukawa, 1964 a, b), rabbit (Janakiraman \& Casida, 1968) and ewe (Ginther, Hawk \& Casida, 1966a). In a preliminary study on water buffaloes, Buch, Shukla \& Hawk (1964) and Buch \& Shukla (1966) reported inhibition of ovulation in the presence of an IUD and noted few shorter oestrous cycles than normal but did not evaluate their observations statistically. Buch et al. (1964) also suggested that IUDs interfere with pituitary LH-activity but this theory was not tested.

The present experiments were planned to study the influence of IUDs on ovulation, oestrous cycle length and pituitary gonadotrophic activity and to evaluate whether the IUD action is directly exerted on the ovary adjacent to the uterine horn containing the device (ipsilateral or local effect) and/or on the opposite ovary (contralateral effect). An attempt was also made through these experiments to find out whether the IUD effect is mediated through the pituitary gland (systemic effect).

\section{MATERIALS AND METHODS}

Thirty-six, Surti buffalo heifers of 3 to 4 years of age and with a mean cycle length of 23.4 days were randomly divided into four equal groups. Group 1 consisted of control animals receiving sham operations in which similar surgical procedures to the treated groups were carried out and both uterine horns were incised in the anterior one-third and sutured. Heifers of Groups 2, 3 and 4 were fitted with IUDs in the uterine horn on the same side as that on which ovulation occurred (ipsilateral), in the opposite side (contralateral) and in both the uterine horns (bilateral).

The IUD, a polyethylene plastic coil of $4 \mathrm{~cm}$ in length and $2 \mathrm{~cm}$ outer diameter prepared as described by Buch et al. (1964), was surgically anchored at laparotomy through a mid-ventral incision into the anterior one-third of the uterine horn by means of Vetafil sutures about $72 \mathrm{hr}$ after the exhibition of heat when all the heifers were found to have ovulated. A combination of chloral hydrate and magnesium sulphate was administered intravenously as a general anaesthetic. Tests for the occurrence of oestrus with a vasectomized bull were carried out three times a day at approximately equal intervals during the post-treatment cycles. Bellowing and mucus discharge were taken as supporting signs of heat. Rectal palpation was carried out where the signs of heat were inconclusive. More than one criterion was needed to judge the presence of heat since buffaloes, as opposed to cows, do not exhibit pronounced signs of oestrus and the incidence of silent heat is more common, making heat detection very difficult (Bhattacharya, 1968). Palpation to detect the development of a follicle or corpus luteum (CL) was carried out three times a week from the first post-treatment oestrus. Apart from one control heifer which was slaughtered during the first post-treatment heat in order to complete the the experiment within the breeding season, heifers were slaughtered $30 \mathrm{hr}$ 
after the second or subsequent post-treatment oestrus. It was necessary to make the exception since the seasonal variation in the female buffalo is more pronounced than in the cow. Buffaloes show more sexual activity during the rainy season and cooler months than in hot weather (Bhattacharya, 1968). Since the time of slaughter was based on the time of exhibition of heat, heifers were allowed to continue for one or more cycles where the occurrence of heat was doubtful and were then slaughtered at a clearly defined subsequent heat. The original grouping of ipsilaterally, contralaterally, bilaterally treated and shamoperated heifers was carried through the slaughter cycle. The occurrence of ovulation or development of a follicle either on the side of the IUD or on the opposite side was noted on rectal palpation. As there was no difference either in the development of these structures or in the length of the oestrous cycles, no attempt was made to separate the post-treatment cycles among themselves or to differentiate between the treatment and post-treatment cycles.

Reproductive tracts were collected and the following characteristics were observed at slaughter:

(a) Total ovarian weight: both the ovaries were cleaned and weighed with their adnexae.

(b) Total follicular fluid weight: after the total weight was taken for (a), the CL, if present, was removed and the ovarian stroma was sliced into small pieces, blotted with filter paper and weighed. The difference between (a) and the weight of ovarian stroma together with the $\mathrm{CL}$, was taken as the total follicular fluid weight. Uterine horns were inspected macroscopically for any pathological condition. The data were subjected to analysis of variance (Snedecor, 1961) and the group differences were tested by Duncan's multiple range test.

The anterior pituitary glands were recovered at slaughter, cleaned, weighed, freeze-dried and then sent to Dr L. E. Casida's laboratory at Wisconsin. For the purposes of pituitary bioassay, the heifers fitted with unilateral IUDs were re-classified at the time of slaughter as either ipsilateral or contralateral on the basis of the presence of new ovulation or follicular development in relation to the location of the IUD. During the slaughter cycle, two heifers of the original, ipsilateral group developed a follicle or ovulated on the contralateral side and were consequently re-classified with the contralateral group. The reverse occurrence in a further five heifers resulted in their subsequent re-classification with the ipsilateral group. A total of twelve ipsilateral and six contralateral heifers was recorded for the purpose of pituitary gland assays.

\section{LH assay}

LH activity was estimated by the ovarian ascorbic acid depletion test (Parlow, 1961) using 26-day-old Holtzman rats. Each gland was assayed separately in three doses of $0.15,0.45$ and $1.35 \mathrm{mg}$ of powder using two rats per dose. Both ovaries were removed, cleaned and weighed and ascorbic acid was estimated by the method of Mindlin \& Butler (1938). Ascorbic acid content was adjusted for ovarian weight by co-variance analysis (Sakiz \& Guillemin, 1963).

FSH assay

Some pooling of powder was necessary because of the small size of the glands. 
Random sub-groups of three buffaloes were formed within each treatment group and pools of $330 \mathrm{mg}$ of powder were made from their pituitary glands, each gland contributing to the pool in proportion to its weight. Each pool was tested for HGG-synergizing (FSH) activity by a modification of the method of Steelman \& Pohley (1953). The rats (30-day Holtzman strain) received $80 \mathrm{mg}$ of pituitary powder each. The powder was packed in two No. 5 gelatin capsules and these were implanted subcutaneously in the shoulder region. The rats were injected with a total of 25 i.u. HGG in six injections over a 3-day period and were killed $36 \mathrm{hr}$ after the last HCG injection, when the ovaries were removed, cleaned and weighed. The remaining powder of all pools was combined and additional rats (three per dose) were treated similarly, except that they received either 40,80 or $160 \mathrm{mg}$ of the pituitary powder. The resulting standard curve was found to be linear. This was essential to know whether or not the treatment groups showed average responses within a linear response curve. Both data for FSH and LH activities were analysed by analysis of variance (orthogonal comparisons).

\section{RESULTS}

\section{Oestrous cycle length}

The control heifers had an average cycle length of $21 \cdot 1$ days and a mean pre-operative cycle length of 22.8 days. The difference between the pre-operative and post-operative cycles was not significant, showing that there was no effect of the surgery itself on oestrous cycle length. The ipsilateral, contralateral and bilateral groups showed an average cycle length of 10.95, 11.60 and 11.53 days, respectively. These shorter cycles were significantly different $(P<$ 0.01 ) from that of the control animals as well as that of the pre-treatment cycle length of the treated groups. (Mean pre-treatment cycle length was 23.8, 22.9 and 23.9 days for ipsilateral, contralateral and bilateral groups, respectively.) The three IUD-treated groups did not, however, show any difference between themselves (Table 1). Twenty-seven ipsilateral and seventeen contralateral cycles occurred after the insertion of an IUD (from treatment cycle to slaughter cycle). These cycles had respective mean lengths of 10.8 and 11.9 days and were not significantly different from each other. The mean cycle lengths of operative ( 11.7 days) and post-operative (11.2 days) cycles were also not different from each other.

\section{Ovulation}

Clear-cut ovulations were observed in eight out of nine control heifers at slaughter and one heifer did not develop any follicle or cL. Six of the eight ovulations occurred in the right ovaries. One heifer ovulated in each of the ipsilateral and contralateral groups. In the ipsilateral group, the ovulation that occurred was on the non-IUD side. In the contralateral group, the ovulation was on the IUD side but the device was found to be in the uterine body and not in the cranial region of the horn. In the bilateral group, three heifers were found to have ovulated at slaughter. Two ovulated on the right side and in one of these the IUD had penetrated into the myometrium. In the other, it was 


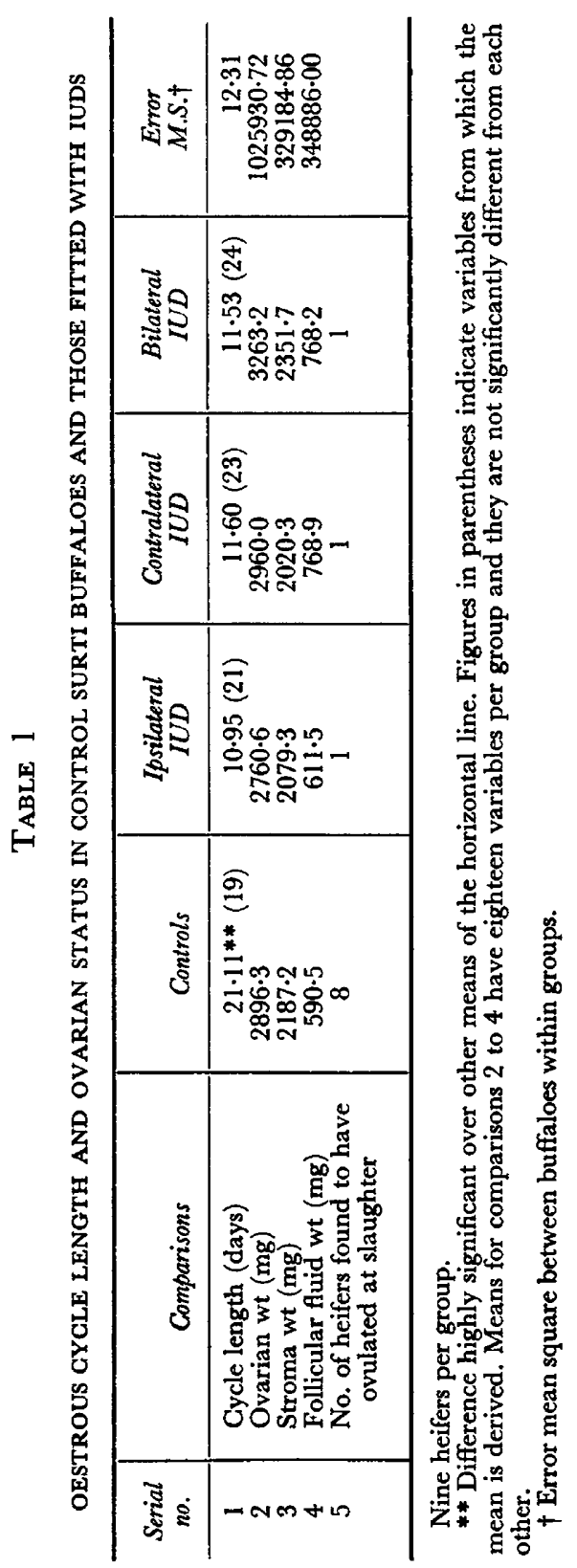


correctly sited. The third heifer ovulated on the left side and the IUD was in place. Rectal palpation data for the pre-slaughter cycle(s) indicated that IUD heifers did develop large follicles which were luteinized and hard to feel but those structures subsequently regressed without ovulation. There were eight ovulations in the treated groups in the pre-slaughter cycles but the CL (mean CL size for treated groups was $10.4 \mathrm{~mm}$ against $10.8 \mathrm{~mm}$ for control group) regressed prematurely leading to shorter cycles. These results were in support of the preliminary work (Buch et al., 1964).

\section{Ovarian characteristics}

There was no significant difference between the groups in total ovarian stroma and follicular fluid weight (Table 1). The heifers that did not ovulate in the treated groups developed luteinized follicles with an average diameter of $18.8 \mathrm{~mm}$ (range, 12 to $26 \mathrm{~mm}$ ) which may be compared with the normal follicles (mean size $10 \mathrm{~mm}$ ) that occur in cyclic heifers. When sliced, the former

Table 2

PITUITARY GHARACTERISTICS OF CONTROL BUFFALO HEIFERS AND THOSE FITTED WITH IUDS

\begin{tabular}{l|c|c|c}
\hline \multicolumn{1}{c|}{ Treatment groups } & $\begin{array}{c}\text { Anterior } \\
\text { pituitary wt } \\
(\mathrm{mg})\end{array}$ & $\begin{array}{c}\text { Test rat } \\
\text { ovarian ascorbic } \\
\text { acid }(\mu \mathrm{g})\end{array}$ & $\begin{array}{c}\text { Test rat } \\
\text { ovarian } \\
\text { wt }(\mathrm{mg})\end{array}$ \\
\hline Controls (S) & $151 \cdot 6(9)^{*}$ & $787 \cdot 1 \dagger$ & $133 \cdot 3 \ddagger(3) \circlearrowleft$ \\
Ipsilateral IUD (I) & $160 \cdot 5(12)$ & 876.9 & $110.8(4)$ \\
Contralateral IUD (C) & $136 \cdot 3(6)$ & 822.8 & $109 \cdot 8(2)$ \\
Bilateral IUD (B) & $152 \cdot 6(9)$ & 801.5 & $108 \cdot 3(3)$ \\
Error & 2321 & 2794 & 2389 \\
\hline
\end{tabular}

* Number of buffaloes in each group in parentheses.

+ Averages of the sums of six rats for each buffalo; potencies relative to the mean dose-response for the whole experiment were $1.22,0.77,1.02$ and 1.14 for $S, I, C$ and $B$, respectively.

$\mp$ Averages of the pool averages, each pool tested on three rats.

$\S$ Number of pools tested.

were invariably seen to have considerable luteinized tissue and blood clot. Fluid collected from these follicles was either thin and transparent or thick and yellowish.

\section{Pituitary gonadotrophic activity}

Anterior pituitary gland weights did not differ significantly and it was assumed that relative gonadotrophin activities reflect total gland content. Within each of the four treatment groups, there was a linear regression of ovarian ascorbic acid content on dose $(P<0.01)$ with no significant quadratic component. LH activity, the inverse of the ascorbic acid content (Table 2), was not significantly different between the treatment groups. Fs activity, as indicated by the test rat ovarian weight, was highest in the control animals, but again the difference was not significant (Table 2). All treatment groups had average ovarian responses which were higher than the 40-mg group and lower than the 160-mg group used in defining the standard curve. 


\section{DISCUSSION}

The action of an IUD varies from one species to another, although its contraceptive end result is uniform in all species studied. IUDs did not have any effect on the cycle length of the laboratory animals studied, except in guinea-pigs. However, these devices bring about an earlier regression of the CL in the ewe when present in the horn adjacent to the ovary containing the CL than when present in the opposite horn (Ginther et al., 1966c). In the cow, oestrous cycles were shortened (Yamauchi \& Nakahara, 1958) and the IUD action was more pronounced when placed ipsilaterally (Ginther et al., 1966d). Shorter cycles, not significantly different from those of controls, were reported by Buch \& Shukla (1966) in a Kankrej cow and a Surti buffalo fitted with IUDs. Gadgil et al. (1968) observed shorter cycles in goats but could not find any evidence for the preferential action of an ipsilateral, compared with a contralateral, IUD on the life and weight of the cL. In pigs, IUDs did not have any effect on cycle length (Gerrits \& Hawk, 1966). The present data clearly indicate that IUDs inserted ipsilaterally, contralaterally or bilaterally into the anterior third of the uterine horns of Surti buffalo heifers shorten the mean oestrous cycle length to nearly half that of the control heifers.

IUDs were also shown to affect ovulation. Delayed ovulation in the rabbit due to late or diminished release of LH (Janakiraman \& Casida, 1968), failure of ovulation in four out of eighteen Holstein heifers (Hawk, Conely, Brinsfield \& Righter, 1964) and complete blockage of ovulation in Surti buffalo heifers (Buch et al., 1964) in the presence of an IUD have been reported. The present study strongly indicated that twenty-two out of twenty-seven heifers with IUDs had not ovulated at the time of slaughter. The time of slaughter was based on the average time of ovulation, detected by rectal palpation at 6 -hourly intervals, of fourteen heifers for seventeen heats. The average time of ovulation of these heifers was 24.6 hr since the exhibition of heat (range, 21 to $30 \mathrm{hr}$ ). There was no ovulation in $81.5 \%$ of the treated heifers as against the $100 \%$ in the previous experiment (Buch et al., 1964). This difference could be mostly attributed to the larger size of the sample involved in the present experiment. Evaluation of ovulation data in the preliminary study was only based on rectal palpations whereas in the present study, the evaluation was also based on visual assessment at slaughter.

There are few direct studies concerning the interference of pituitary gonadotrophic activity by IUDs. Janakiraman \& Casida (1968) reported that LH activity $11 \mathrm{hr}$ after mating was higher in rabbits fitted with IUDs than in controls. Bhalla, Memon, Woody \& Casida (1969) studied the effects of IUDs on pituitary gonadotrophins in Holstein heifers $26 \mathrm{hr}$ after the detection of oestrus. Relative FSH and LH activities did not differ among treatment groups but anterior pituitary weights were significantly greater in the heifers with IUDs than in the controls. In the present study, the gonadotrophic activity in control heifers was found to be more or less on the same level as in the treated groups in spite of the fact that eight of the nine control heifers ovulated at slaughter while only five of twenty-seven treated heifers did so. Gonadotrophic activity might have been expected to be higher in the treated heifers since most 
of them developed larger follicles but did not ovulate. This may indicate that the synthesis rather than the release of gonadotrophin may have been affected. Further studies are needed to compare the pituitary and hypothalamic activities both before and after the time of ovulation to arrive at a valid conclusion. In the absence of any difference in pituitary activity, the transmission of some unknown uterine factor from the IUD-horn to the non-IUD horn to induce a contralateral effect cannot be ruled out. Such a possibility has been reported for the rat and mouse (Doyle \& Margolis, 1966; Marston \& Kelly, 1969).

\section{ACKNOWLEDGMENTS}

The authors are grateful to Dr R. M. Patel, Dr G. N. Memon, Dr G. F. Mithuji and Mr P. M. Zala of our group for their help in various capacities. This work was supported by a grant from the Ford Foundation.

\section{REFERENCES}

Bhalla, R. C., Memon, G. N., Woody, C. O. \& CAsida, L. E. (1969) Effect of bilateral intra-uterine devices on some pituitary and ovarian characteristics near the time of ovulation in Holstein heifers. F. Anim. Sci. 28, 48.

Bhattacharya, P. (1968) Buffaloes. In: The Artificial Insemination of Farm Animals, 3rd edn. Ed. E. J. Perry. Oxford and IBH Publishing, New Delhi, India.

Buch, N. G. \& ShuKLA, K. P. (1966) Effect of intrauterine plastic devices on reproduction in Surti buffaloes and Kankrej cows. Indian 7. Dairy Sci. 19, 25.

Buch, N. C., ShukLA, K. P. \& HAwK, H. W. (1964) Interference with ovulation by intrauterine plastic devices in Indian water buffaloes. 5th Int. Cong. Anim. Reprod. and A.I., Trento, 2, 242.

Doyte, L. L. \& Margolis, A. J. (1966) The effect of an IUFB on reproduction in mice. F. Reprod. Fert. $11,27$.

GadGIL, B. A., Collins, W. E. \& BuCH, N. G. (1968) Effects of intrauterine spirals on reproduction in goats. Indian F. exp. Biol. 6, 138.

Gerrits, R. G. \& HaWK, H. W. (1966) Effect of intrauterine devices on fertility in pigs. (Abstract). F. Anim. Sci. 25, 1266.

Ginther, O. J., Hawk, H. W. \& CAsida, L. E. (1966a) Pituitary Lh activity of ewes treated with an intrauterine device. F. Anim. Sci. 25, 1262.

Ginther, O. J., Mahajan, S. \& Casida, L. E. (1966b) Local ovarian effects of an intrauterine device in intact and unilaterally ovariectomized guinea pigs. Proc. Soc. exp. Biol. Med. 123, 775.

Ginther, O. J., Pope, A. L. \& Casida, L. E. (1966c) Local effect of an intrauterine plastic coil on the corpus luteum of the ewe. F. Anim. Sci. 25, 272.

Ginther, O. J., Woody, C. O., Janakiraman, K. \& Casida, L. E. (1966d) Effect of an intra-uterine plastic coil on the oestrous cycle of the heifer. F. Reprod. Fert. 12, 193.

Hawk, H. W., Conely, H. H., Brinsfield, T. H. \& Righter, H. F. (1964) Contraceptive effect of plastic devices in cattle uteri. Proc. 2nd int. Conf. Intra-uterine Contraception, New York, pp. 189.

HorIE, T. \& IsHIKuRA, F. (1964a) Studies on the effect of uterine distension on the reproductive functions in cattle. 1) Effect of infusion of foreign body ('artificial gelatinous substances') into the uterus on the ovarian functions. Bull. Chugoku-Shikoku agric. exp. Stn, B, 12, 61.

Horie, T., Ishikura, F. \& Metsukawa, T. (1964b) Studies on the effect of uterine distension on the reproductive functions in cattle. 2) The effect of infusion of foreign body into uterus on the potency of anterior lobe of pituitary. Bull. Chttgoku-Shikoku agric. exp. Stn, B, 12, 69.

Janakiraman, K. \& Casida, L. E. (1968) Ovulation, corpora lutea development and pituitary LH activity in rabbits with in tra-uterine devices. $\mathcal{F}$. Reprod. Fert. 15, 395.

KAR, A. B. (1968) Mechanism of action of intrauterine contraceptive devices. $\mathcal{7}$. scient. ind. Res. 27, 70.

Marston, J. H. \& Kelly, W. A. (1966) The effects and mode of action of intrauterine devices. Vet. Rec. 79,644 .

Marston, J. H. \& Kelly, W. A. (1969) The time and site of contraceptive action of an intrauterine device in the mouse. F. Endocr. 43, 83.

MindLin, R. L. \& BUTLER, A. M. (1938) The determination of ascorbic acid in plasma: a macromethod and micromethod. F. biol. Chem. 122, 673. 
Parlow, A. F. (1961) Bioassay of pituitary luteinizing hormone by depletion of ovarian ascorbic acid. In: Human Pituitary Gonadotropins, p. 300. Ed. A. Albert. C. C. Thomas, Springfield, Ill.

Sakiz, E. \& Guillemin, R. (1963) On the method of ovarian ascorbic acid depletion as a test for luteinizing hormones (LH). Endocrinology, 72, 804.

Snedecor, G. W. (1961) Statistical methods. Allied Pacific Co., Bombay.

Steeluan, S. L. \& Pohley, F. M. (1953) Assay of the follicle stimulating hormone based on the augmentation with human chorionic gonadotropin. Endocrinology, 53, 604.

Yamauchi, M. \& Nakahara, T. (1958) Effects of uterine distension on the oestrous cycle of cattle. Jap. J. Anim. Reprod. 3, 121 